\title{
Chronotype and time-of-day influences on the alerting, orienting, and executive components of attention
}

\author{
Robert L. Matchock $\cdot$ J. Toby Mordkoff
}

Published online: 28 October 2008

(C) Springer-Verlag 2008

\section{Erratum to: Exp Brain Res}

\section{DOI 10.1007/s00221-008-1567-6}

In the published original version of the article, Table 2 contains duplicated mean RTs and error rates for the Neutral and Incongruent trials.

Mean RTs and error rates for the cue type conditions of Spatial, Center, Double, and No Cue should read as follows:

0800 hours

Neutral trials $\quad 421(.3), 459(1.0), 545(.4), 515(1.3)$

Incongruent trials $562(2.6), 632(4.0), 631$ (4.3), $659(3.7)$

1200 hours

Neutral trials $404(.2), 445(.6), 441(1.0), 503(1.3)$

Incongruent trials 554 (2.9), 627 (5.2), 626 (4.9), 647 (4.1)
1600 hours

Neutral trials $\quad 414(.3), 447(.7), 440(1.0), 513(1.1)$

Incongruent trials $561(2.2), 627$ (5.4), $617(3.8), 662$ (4.5)

2000 hours

Neutral trials $\quad 410(.6), 449(.8), 436(.7), 516(1.0)$

Incongruent trials 541 (2.4), 616 (5.7), 611 (4.5), 651 (4.9)

We apologize for any inconvenience that this might have caused.

The authors

The online version of the original article can be found under doi:10.1007/s00221-008-1567-6.

R. L. Matchock ( $\square)$

Department of Psychology, The Pennsylvania State University,

Altoona Campus, E133B Smith Building,

3000 Ivyside Park, Altoona, PA 16601, USA

e-mail: rlm191@psu.edu

J. Toby Mordkoff

Department of Psychology, E11 Seashore Hall,

University of Iowa, Iowa City, IA 52242, USA

e-mail: jonathan-mordkoff@uiowa.edu 